\title{
Synthesis, Structures, and Properties of Two Novel Coordination Polymers with a V-shaped Diphosphonate Ligand
}

\author{
Xiaoxia Lv, ${ }^{[a, b]}$ Sifu Tang, ${ }^{[a]}$ Liangjun Li, ${ }^{[a, b]}$ Xianrui Xu, ${ }^{[a, b]}$ and Xuebo Zhao*[a]
}

Keywords: Diphosphonate ligand; V-shape; Crystal structure; X-ray diffraction; Infrared spectroscopy; Thermogravimetric

Abstract. Two novel coordination polymers, $\left[\mathrm{Cu}\left(\mathrm{H}_{2} \mathrm{~L}\right)(\right.$ bipy $\left.)\left(\mathrm{H}_{2} \mathrm{O}\right)_{2}\right]$. $\mathrm{H}_{2} \mathrm{O}(\mathbf{1})$ and $\left[\mathrm{Ni}_{2}\left(\mathrm{H}_{2} \mathrm{~L}\right)(\text { bipy })_{2.5}\left(\mathrm{H}_{2} \mathrm{O}\right)_{6}\right] \cdot\left(\mathrm{H}_{2} \mathrm{~L}\right) \cdot 7 \mathrm{H}_{2} \mathrm{O}$ (2) with the $\mathrm{V}$ shaped diphosphonate ligand (2,4,6-trimethyl-1,3-phenylene)bis(methylene)diphosphonic acid $\left(\mathrm{H}_{4} \mathrm{~L}\right)$ were synthesized via hydrothermal reactions in the presence of auxiliary ligand $4,4^{\prime}$-bipyridine. Their structures were determined by single-crystal X-ray diffraction and fur- ther characterized by elemental analysis, infrared spectroscopy (IR), and thermogravimetric analysis (TGA). Compound $\mathbf{1}$ crystallizes in the Pnma space group and compound $\mathbf{2}$ crystallizes in the $P 2_{1} 2_{1} 2$ space group. They display square-grid layer and bilayer two-dimensional network, respectively.

\section{Introduction}

Due to the versatile fascinating structures as well as the potential applications in many fields such as gas storage, ${ }^{[1]}$ separation, ${ }^{[2]}$ catalysis, ${ }^{[3]}$ molecule recognition, ${ }^{[4]}$ fluorescence, ${ }^{[5]}$ and magnetism, ${ }^{[6]}$ the design and synthesis of novel metal-organic frameworks (MOFs) or coordination polymers have been one of the active fields in materials chemistry. It is well-known that MOFs are organic-inorganic hybrid materials constructed from the assembly of the organic ligands (such as carboxylate and phosphonate ligands) with metal or metal clusters, in which the ligands act as linkers and metal/metal clusters act as nodes. ${ }^{[7]}$ Compared to the conventionally used carboxylate and pyridine based ligands, phosphonate ligands were less frequently reported in the construction of coordination polymers. This is mainly because that they form stronger bonds with metal atoms than carboxylate ligands which results in lower solubility and accordingly lead to the difficulty in forming single crystals for structural determination. ${ }^{[8]}$ In addition, phosphonic acid group contains three oxygen atoms capable of bonding to metals, so it is difficult to predict the coordination mode and deprotonation state of the ligand. ${ }^{[9]}$ But these characteristics make many phosphonate ligands based coordination polymers exhibit impressive properties, such as the unusual topology, ${ }^{[10]}$ and ultra high thermal stability ${ }^{[11]}$ which are the main drawbacks of many carboxylate based coordination polymers. By using linear aliphatic diphosphonate ligands and co-

* Prof. Dr. X. Zhao

Fax: +86 53280662728

E-Mail: zhaoxb@qibebt.ac.cn

[a] Qingdao Institute of Bioenergy and Bioprocess Technology

Chinese Academy of Sciences

266101, Qingdao, P. R. China

[b] University of Chinese Academy of Sciences

100049, Beijing, P. R. China

$\square$ Supporting information for this article is available on the WWW under http://dx.doi.org/10.1002/zaac.201300185 or from the author.
balt(II) and magnesium(II) salts, Distler et al. synthesized several phosphonate-based coordination polymers with 1D chain, 2D layer, and 3D network structures. The cobalt complexes exhibited antiferromagnetic properties. ${ }^{[12]}$ Based on linear aromatic diphosphonate ligand, $\mathrm{Cao}$ et al. synthesized two isostructural 3D metal diphosphonates $\left.\mathrm{M}_{2} \mathrm{O}_{3} \mathrm{PC}_{6} \mathrm{H}_{4} \mathrm{PO}_{3}\right)\left(\mathrm{H}_{2} \mathrm{O}\right)_{2}$ $\left[\mathrm{M}=\mathrm{Co}^{\mathrm{II}}\right.$ or $\left.\mathrm{Ni}^{\mathrm{II}}\right]$, in which, each $\left[\mathrm{CPO}_{3}\right]$ tetrahedron is connected to four $\left[\mathrm{MO}_{6}\right]$ octahedral forming inorganic layer and the further linking of these layers by phenyl groups of the diphosphonate ligands resulting in a pillared layered structure. ${ }^{[13]}$ Besides, some coordination polymers based on other linear aliphatic or aromatic diphosphonic acid ligands with different sizes and configurations were synthesized. ${ }^{[14]}$ However, the V-shaped phosphonate ligands, which were constructed by the substitution on the meta-position of the phenyl ring forming an angle of about $120^{\circ}$ between two phosphonate groups, have been seldom used before. Previous studies ${ }^{[15]}$ show that the V-shaped ligands are apt to afford the zeolite like structures, such as imidazole based ligands, ${ }^{[16]}$ isophthalate substituted ligands, ${ }^{[17]}$ etc. In additional, for metal carboxylates, studies have also shown that the resulting molecular architecture could be tailored by altering the bridging angle and the size of the linker. ${ }^{[18]}$ In the context of this, we designed and synthesized a V-shaped ligand, $\mathrm{H}_{4} \mathrm{~L}$ (2,4,6-trimethyl-1,3-phenylene)bis(methylene) diphosphonic acid), and obtained two novel coordination polymers, $\left[\mathrm{Cu}\left(\mathrm{H}_{2} \mathrm{~L}\right)(\right.$ bipy $\left.)\left(\mathrm{H}_{2} \mathrm{O}\right)_{2}\right] \cdot \mathrm{H}_{2} \mathrm{O}(\mathbf{1})$ and $\left[\mathrm{Ni}_{2}\left(\mathrm{H}_{2} \mathrm{~L}\right)(\text { bipy })_{2.5}\left(\mathrm{H}_{2} \mathrm{O}\right)_{6}\right] \cdot\left(\mathrm{H}_{2} \mathrm{~L}\right) \cdot 7 \mathrm{H}_{2} \mathrm{O}(2)$, by using this ligand and transition metal salts. The structures were determined from single-crystal X-ray analysis. In addition, we further studied the infrared spectroscopic and thermogravimetric properties of these two novel coordination polymers.

\section{Results and Discussion \\ Description of the Structures}

The following structures discussion is based on CIF files of complexes $\mathbf{1}$ and 2, and the final formulas of the two com- 
plexes are further determined by elemental analyses, infrared spectra, and thermogravimetric studies.

\section{Structure of Compound 1}

The X-ray crystallographic analysis indicates that compound 1 crystallizes in the Pnma space group and the structure shows a square-grid 2D layered network. The asymmetric unit includes one $\mathrm{Cu}^{\mathrm{II}}$ ion, one partly deprotonated $\mathrm{H}_{2} \mathrm{~L}^{2-}$ ligand, one 4,4'-bipyridine, two coordinated water molecules, and one guest water molecule (Figure S1, Supporting Information). The coordination arrangement around the copper atom is between trigonal-bipyramidal and square-pyramidal structure $(\tau=$ 0.425). ${ }^{[3 \mathrm{a}, 19]}$ The axial positions are occupied by two nitrogen atoms (N1 and N2A; A: $-1 / 2+x, y, 3 / 2-z)$ from two different $4,4^{\prime}$-bipyridine molecules and there are three oxygen atoms $(\mathrm{O} 3, \mathrm{O} 3 \mathrm{~B}, \mathrm{O} 1 \mathrm{~W} ; \mathrm{B}: x, 1 / 2-y, z)$ of two phosphonate groups from two different $\mathrm{H}_{2} \mathrm{~L}^{2-}$ ligands and one aqua ligand in the equatorial positions. The bond lengths of $\mathrm{Cu}-\mathrm{O}$ (phosphonate), $\mathrm{Cu}-\mathrm{O}$ (water), and $\mathrm{Cu}-\mathrm{N}$ are $1.940 \AA, 2.174 \AA$ and $2.022 \AA$, respectively. The torsion angles of $\mathrm{O} 3-\mathrm{Cu} 1-\mathrm{O} 3 \mathrm{~B}$ in the equatorial plane and $\mathrm{N} 1-\mathrm{Cu} 1-\mathrm{N} 2 \mathrm{~A}$ in the axial plane are $176.0(3)^{\circ}$ and $150.5(3)^{\circ}$, respectively (see Table S1, Supporting Information). All of these are comparable to those reported for the bond lengths of $\mathrm{Cu}-\mathrm{O}, \mathrm{Cu}-\mathrm{N}$, and the torsion angles of $\mathrm{O}-\mathrm{Cu}-\mathrm{O}$ and $\mathrm{N}-\mathrm{Cu}-\mathrm{N}$ by Muppidi et al. ${ }^{[20]}$ Both phosphonate groups of the $\mathrm{H}_{2} \mathrm{~L}^{2-}$ ligand are singly protonated based on the requirement of charge balance and $\mathrm{P}-\mathrm{O}$ bond lengths, and each diphosphonate ligand bridges two $\mathrm{Cu}^{\mathrm{II}}$ ions.

Each adjacent two $\mathrm{CuO}_{3} \mathrm{~N}_{2}$ polyhedra are bridged by phosphonate groups of $\mathrm{H}_{2} \mathrm{~L}^{2-}$ and generated an infinite line-chain along the $b$ axis through $\mathrm{Cu}-\mathrm{O}$ bonds. A two-dimensional square-grid layer (Figure 1a) is constructed by interconnecting the neighboring chains through 4,4'-bipyridine with $\mathrm{Cu}-\mathrm{N}$ bonds. Figure $1 \mathrm{~b}$ shows the separation of the layers as viewed down the $a$ axis.

\section{Structure of Compound 2}

Compound 2 exhibits a bilayered network structure (Figure 2b). As shown in Figure S2 (Supporting Information), each asymmetric unit contains two pseudo-octahedral nickel cations, two partly deprotonated $\mathrm{H}_{2} \mathrm{~L}^{2-}$ ligands (one is coordinated to the nickel ion $\mathrm{Ni} 2$ and the other is dispersed in the unit), two and half 4,4'-bipyridine molecules, six coordinated, and seven guest water molecules. The first nickel cation, Ni1, is coordinated by three oxygen atoms from three water molecules and three nitrogen atoms from three $4,4^{\prime}$-bipyridine to give a mer-octahedral arrangement with coordination angles in the range of $83.9(3)-175.9(4)^{\circ}$. The Ni2 ion is coordinated by four oxygen atoms $(\mathrm{O} 4 \mathrm{~W}, \mathrm{O} 5 \mathrm{~W}, \mathrm{O} 6 \mathrm{~W}, \mathrm{O} 1)$ and two nitrogen atoms $(\mathrm{N} 3, \mathrm{~N} 4)$ to attain a trans-octahedral arrangement. O4W, $\mathrm{O} 5 \mathrm{~W}$, and $\mathrm{O} 6 \mathrm{~W}$ come from three water molecules, and $\mathrm{O} 1$ belongs to phosphonate group of diphosphonate ligand. N3 and N4 come from two 4,4'-bipyridine.

Mer $-\mathrm{NiO}_{3} \mathrm{~N}_{3}$ and trans $-\mathrm{NiO}_{4} \mathrm{~N}_{2}$ octahedral units are arranged in turn to generate two similar dispersed $1 \mathrm{D}$ chains

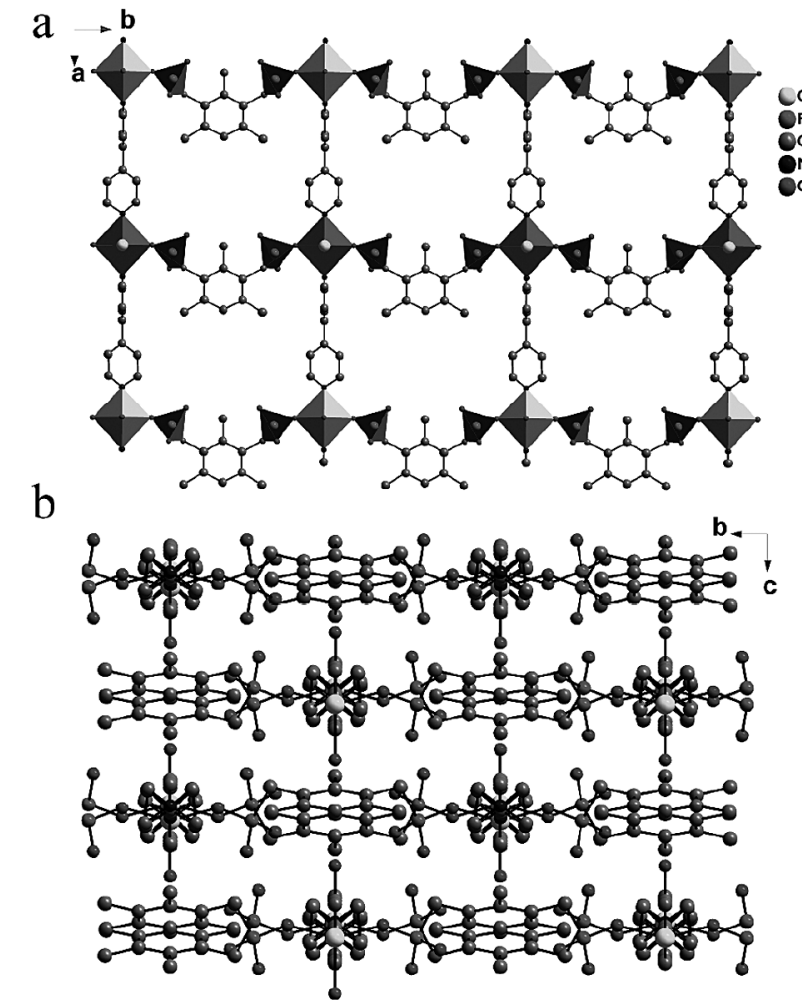

Figure 1. (a) Single square-grid layer in compound $\mathbf{1}$ with $\mathrm{Cu}$ and $\mathrm{P}$ shown as polyhedra; (b) View of the structure of compound $\mathbf{1}$ down $a$ direction.

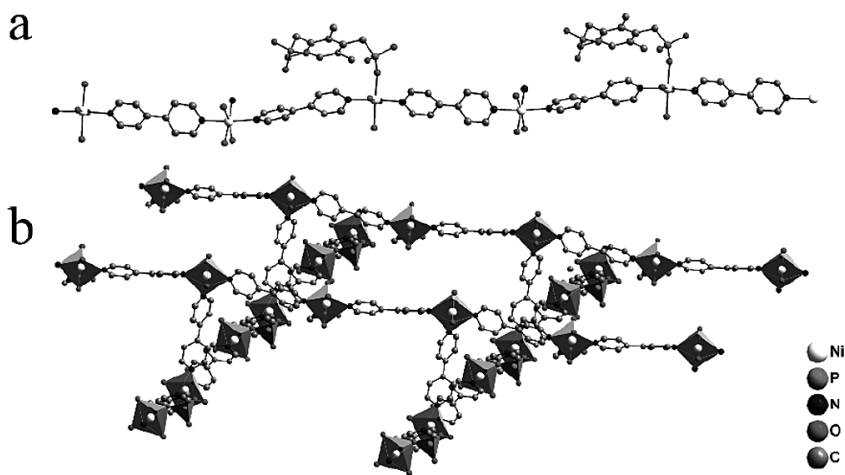

C

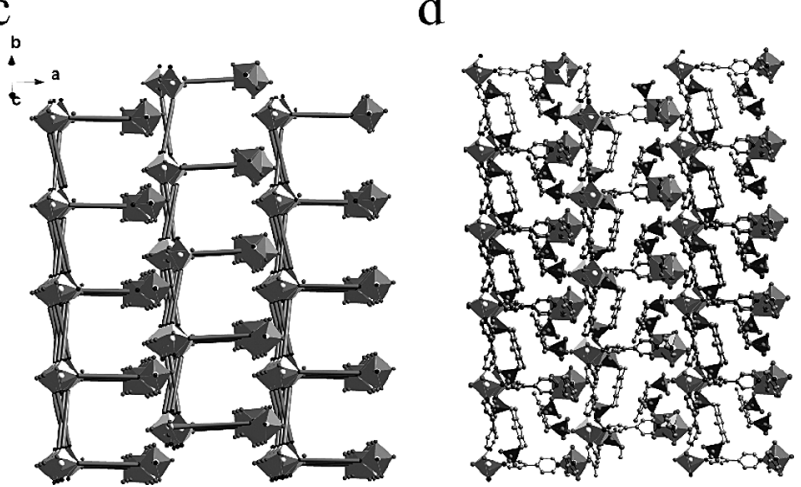

Figure 2. (a) 1D infinite chain along the diagonal direction of the 100 plane; (b) bilayer in compound 2 with $\mathrm{NiO}_{3} \mathrm{~N}_{3}, \mathrm{NiO}_{4} \mathrm{~N}_{2}$, and $\mathrm{PO}_{3}$ shown as polyhedra (only gives the coordinated $\mathrm{H}_{2} \mathrm{~L}^{2-}$ ); (c) simplified supramolecular dispersed bilayers structure; (d) the disperse bilayers of compound $\mathbf{2}$ (guest water molecules are omitted for clarity). 
along the two cross diagonal directions in two parallel [100] and [100] planes (Figure 2a). These 1D chains are joined by 4,4'-bipyridine to construct a bilayered network (Figure 2b) like depicted by M. J. Zaworotko et al. ${ }^{[21]}$ and Figure $2 \mathrm{c}$ shows the simplified supramolecular structure with $\mathrm{NiO}_{3} \mathrm{~N}_{3}$ and $\mathrm{NiO}_{4} \mathrm{~N}_{2}$ motifs. There are some dispersed $\mathrm{H}_{2} \mathrm{~L}^{2-}$ ligands between each two neighboring bilayers and Figure 2d displays the whole structure excepting guest water molecules. Probably due to the existing of dispersed $\mathrm{H}_{2} \mathrm{~L}^{2-}$, these bilayers do not form interdigitating structure but simple parallel packing. ${ }^{[22]}$

\section{PXRD and Thermogravimetric Analyses}

The powder X-ray diffraction (PXRD) patterns of the two compounds are shown in Figure 3. Both of the two PXRD curves are consistent with the corresponding simulated patterns from the single-crystal structure data. It demonstrates that the as-synthesized samples are of high purity.

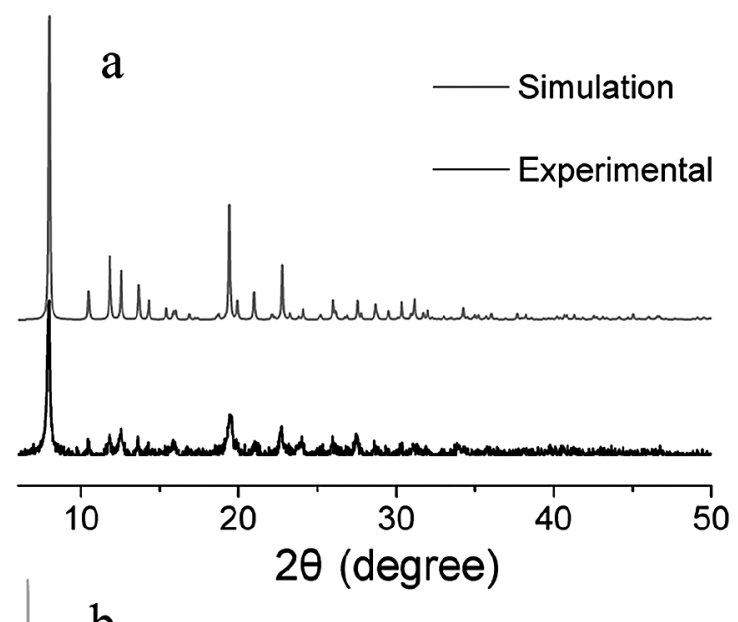

b

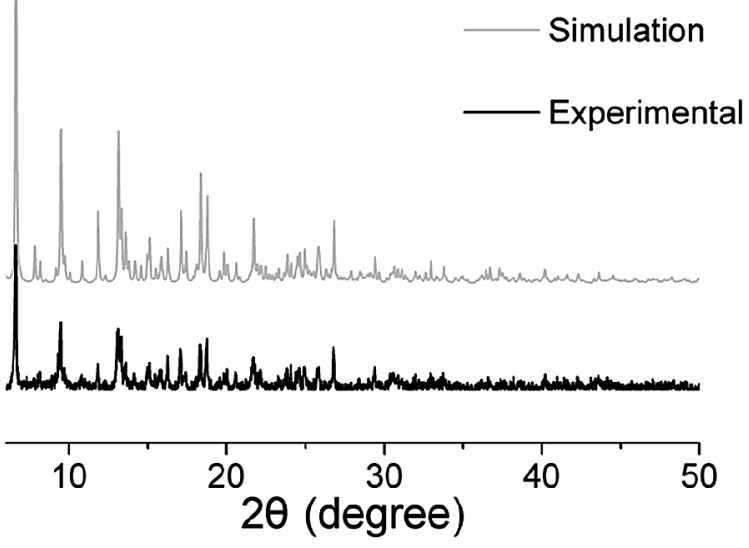

Figure 3. Simulated PXRD pattern (gray) and experimental PXRD pattern (black) of $\mathbf{1}$ (a) and $\mathbf{2}$ (b).

To disclose the stabilities of compounds $\mathbf{1}$ and $\mathbf{2}$, thermogravimetric analyses (TGA) were performed from room temperature to $800{ }^{\circ} \mathrm{C}$ (Figure 4). For compound 1, there are three weight loss steps. The first weight loss began at $60{ }^{\circ} \mathrm{C}$ and was completed at $160{ }^{\circ} \mathrm{C}$. The observed weight loss of $9.2 \%$ corresponds to the removal of one lattice water and two coordi- nation water molecules (calculated: $9.3 \%$ ). The other two steps indicate the successive decomposition of the two-dimension square-grid layer supermolecular structure, and at the end of the measurement $\left(800{ }^{\circ} \mathrm{C}\right)$ the total weight loss is approximately $52.4 \%$. From the curve of compound 2 , a steep weight loss in the temperature range from 40 to $145^{\circ} \mathrm{C}$ corresponds to the removal of seven lattice water molecules and six coordination water molecules (calculated: $17.31 \%$; observed: $17.51 \%$ ). Finally the total weight loss was about $54.64 \%$ at $800{ }^{\circ} \mathrm{C}$.

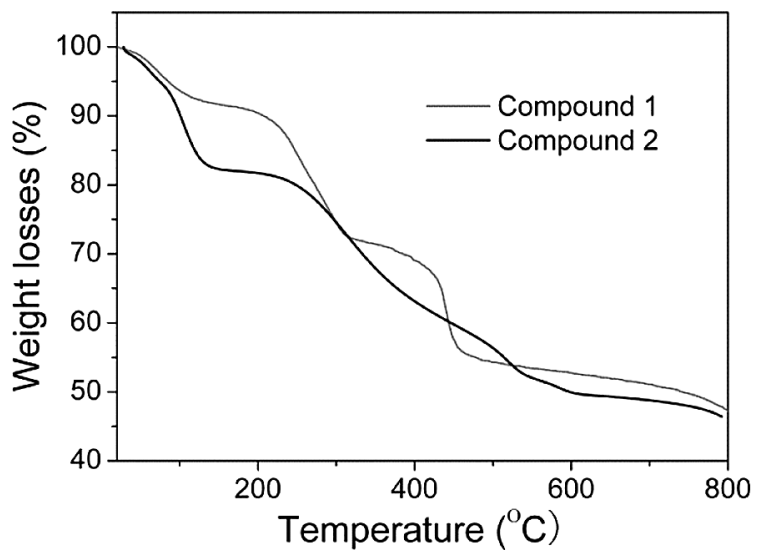

Figure 4. TGA diagrams of compound $\mathbf{1}$ (gray) and $\mathbf{2}$ (black).

\section{Conclusions}

In the presence of auxiliary 4,4'-bipyridine, two supramolecular coordination networks were constructed from selfassembly of flexible V-shaped diphosphonate ligand: (2,4,6trimethyl-1,3-phenylene)bis(methylene) diphosphonic acid $\left(\mathrm{H}_{4} \mathrm{~L}\right)$ with two central transition metal atoms $\mathrm{Cu}^{\mathrm{II}}$ and $\mathrm{Ni}^{\mathrm{II}}$. The difference of these two structures could be ascribe to the different coordination mode of the central metal atoms or the ratios of metal, ligand, and second ligand 4,4'-bipyridine. The structures and properties were confirmed by single-crystal $\mathrm{X}$ ray diffraction, elemental analysis, infrared spectroscopy, powder X-ray diffraction, and thermogravimetric analysis. Other properties such as magnetism will be further studied.

\section{Experimental Section}

Synthesis:1,3-Bis(bromomethyl)-2,4,6-trimethylbenzene was synthesized by the procedure of Vander Made et al. ${ }^{[23]}$ All other chemicals were obtained from commercial sources and used without further purification.

(2,4,6-Trimethyl-1,3-phenylene)bis(methylene) Diphosphonic Acid $\left(\mathbf{H}_{\mathbf{4}} \mathbf{L}\right)$ : Triethylphosphite and 1,3-bis(bromomethyl)-2,4,6-trimethylbenzene were dissolved in toluene and refluxed for $12 \mathrm{~h}$ in a nitrogen atmosphere. Afterwards the solvent was removed. Excessive $37 \%$ hydrochloric acid was added into the resulting pale yellow oil and refluxed for $2 \mathrm{~d}$. During this period white solid was formed. At last, the solid was filtered off, washed with water and dried in air (see Scheme $\mathrm{S} 1$, Supporting Information). $\mathrm{C}_{11} \mathrm{H}_{18} \mathrm{O}_{6} \mathrm{P}_{2}$ : C $42.87, \mathrm{H} 5.89 \%$; found C 42.93; H 5.66\%. ${ }^{1}$ H NMR (600 MHz, [D 6 DMSO, ppm): $\delta=6.79$ 
(s, $1 \mathrm{H}, \mathrm{Ar}-\mathrm{H}$ ), 3.01 (d, $\left.4 \mathrm{H}, \mathrm{Ar}-\mathrm{CH}_{2}\right) ; 2.33$ (s, $3 \mathrm{H}, \mathrm{Ar}-\mathrm{CH}_{3}$ ); 2.28 (s, $6 \mathrm{H}, \mathrm{Ar}-\mathrm{CH}_{3}$ ). IR (selected data, $\mathrm{KBr}$ ): $\tilde{\mathrm{v}}=3427$ (s), 2924 (w), 1632 (m), 1464 (w), 1411 (w), 1182 (m), 1139 (m), 1047 (vs), 1001 (vs), 954 (vs), 803 (w), 774 (w), 709 (w), 553 (w), 490 (m) cm-1.

Synthesis of $\left[\mathrm{Cu}\left(\mathrm{H}_{2} \mathrm{~L}\right)(\right.$ bipy $\left.)\left(\mathrm{H}_{2} \mathrm{O}\right)_{2}\right] \cdot \mathrm{H}_{2} \mathrm{O}$ (1): A mixture of $\mathrm{H}_{4} \mathrm{~L}$ $(0.0616 \mathrm{~g}, 0.2 \mathrm{mmol}), \mathrm{CuSO}_{4} \cdot 5 \mathrm{H}_{2} \mathrm{O}(0.0499 \mathrm{~g}, 0.2 \mathrm{mmol})$, and $4,4^{\prime}$ bipyridine $(0.062 \mathrm{~g}, 0.4 \mathrm{mmol})$ was dissolved in distilled water $(10 \mathrm{~mL})$ and stirred at room temperature for $30 \mathrm{~min}$ in a Teflon-lined autoclave $(23 \mathrm{~mL})$ (Scheme 1). Afterwards the $\mathrm{pH}$ value was altered to about 4 with $1 \mathrm{M} \mathrm{NaOH}$, and the autoclave was heated at $140{ }^{\circ} \mathrm{C}$ for $3 \mathrm{~d}$. After being cooled to room temperature slowly ( $24 \mathrm{~h}$ ), blue crystals of compound 1 were filtered off and washed with water. The yield was about $62 \%$ based on $\mathrm{H}_{4} \mathrm{~L} \cdot \mathrm{C}_{21} \mathrm{H}_{30} \mathrm{CuN}_{2} \mathrm{O}_{9} \mathrm{P}_{2}$ : calcd. C 43.49; H 5.21; N 4.83\%; found C 43.28; H 5.24; N $4.78 \%$. IR (selected data, $\mathrm{KBr}): \tilde{v}=3419(\mathrm{~s}), 2926(\mathrm{w}), 1635(\mathrm{~m}), 1615(\mathrm{~s}), 1536(\mathrm{~m}), 1467(\mathrm{w})$, 1414 (w), 1220 (m), 1117 (vs), 1101 (vs), 1080 (s), 946 (m), 919 (s), $814(\mathrm{~m}), 774(\mathrm{w}), 646(\mathrm{~m}), 510(\mathrm{~m}) \mathrm{cm}^{-1}$.

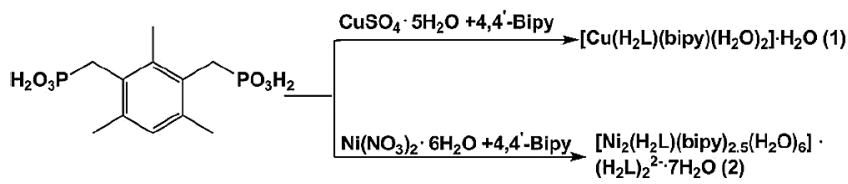

Scheme 1. Synthesis of compounds $\mathbf{1}$ and $\mathbf{2}$.

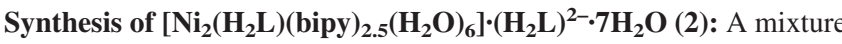
of $\mathrm{H}_{4} \mathrm{~L}(0.0616 \mathrm{~g}, 0.2 \mathrm{mmol}), \mathrm{Ni}\left(\mathrm{NO}_{3}\right)_{2} \cdot 6 \mathrm{H}_{2} \mathrm{O}(0.08724 \mathrm{~g}, 0.3 \mathrm{mmol})$ and $4,4^{\prime}$-bipyridine $(0.04685 \mathrm{~g}, 0.3 \mathrm{mmol})$ was dissolved in distilled water $(10 \mathrm{~mL})$. The further process was the same as that for compound 1 (Scheme 1). Green crystals of compound 2 were collected in about $56 \%$ yield based on $\mathrm{H}_{4} \mathrm{~L} . \mathrm{C}_{47} \mathrm{H}_{78} \mathrm{~N}_{5} \mathrm{Ni}_{2} \mathrm{O}_{25} \mathrm{P}_{4}$ : calcd. C 41.68; $\mathrm{H} 5.80$ N 5.17\%; found C 41.82; H 5.75; N 5.21\%. IR (selected data, KBr): $\tilde{\mathrm{v}}=3416(\mathrm{~s}), 2993(\mathrm{w}), 1610(\mathrm{~s}), 1537(\mathrm{~m}), 1493(\mathrm{w}), 1416(\mathrm{~m}), 1227$ (m), 1127 (s), 1059 (s), 939 (w), 909 (m), 819 (m), 750 (w), 636 (m), $513(\mathrm{~m}) \mathrm{cm}^{-1}$

Single Crystal Structure Determination: Single crystals X-ray diffraction measurements of compounds $\mathbf{1}$ and $\mathbf{2}$ were carried out with a
Bruker SMART APEXII CCD diffractometer with graphite monochromatic Mo- $K_{\alpha}$ radiation $(\lambda=0.71073 \AA)$ at room temperature. The SMART software was used for data acquisition and data integration was undertaken with SAINT program. ${ }^{[24]}$ Multi-scan empirical absorption corrections were applied to process the data using the SADABS program. ${ }^{[25]}$ Crystal structures were solved by direct methods using SHELXS. ${ }^{[26]}$ Subsequent difference Fourier analyses and least-squares refinement with SHELXL-97 program package ${ }^{[27]}$ allowed the location of the atom positions. All non-hydrogen atoms were refined anisotropically and the organic hydrogen atoms were positioned geometrically. Most of the hydrogen atoms were located from the difference Fourier maps and refined isotropically. While other hydrogen atoms are added into a fixed geometry. Hydrogen atoms of guest water molecules in compound 2 were not included in the refinements. The protonation of the phosphonate groups are based on the requirement of charge balance and $\mathrm{P}-\mathrm{O}$ bond lengths. Crystallographic details for compounds $\mathbf{1}$ and 2 are summarized in Table 1 . Selected bond lengths and bond angles are listed in Table S1.

Crystallographic data (excluding structure factors) for the structures in this paper have been deposited with the Cambridge Crystallographic Data Centre, CCDC, 12 Union Road, Cambridge CB21EZ, UK. Copies of the data can be obtained free of charge on quoting the depository numbers CCDC-902266 and CCDC-902268. (Fax: +44-1223-336-033; E-Mail: deposit@ccdc.cam.ac.uk, http://www.ccdc.cam.ac.uk).

Physical Properties: Elemental analyses for $\mathrm{C}, \mathrm{H}$, and N were carried out with a German Elementary Vario EL cube instrument. IR spectra were performed with a Nicolet 6700 FTIR spectrometer in the region $4000-400 \mathrm{~cm}^{-1}$ using $\mathrm{KBr}$ pellets. Thermogravimetric analyses were recorded with a NETZSCH STA 449F3 unit at a heating rate of $10{ }^{\circ} \mathrm{C}$ $\mathrm{min}^{-1}$ in a nitrogen atmosphere. Solution ${ }^{1} \mathrm{H}$ NMR spectra were recorded with a Bruker AVANCE-III NMR $(600 \mathrm{MHz})$. Power X-ray diffraction (XRD) patterns were collected with a D8 Advance X-ray diffractometer using $\mathrm{Cu}-K_{\alpha}$ radiation $(\lambda=0.154 \mathrm{~nm})$.

Supporting Information (see footnote on the first page of this article): Coordination environment of the $\mathrm{Ni}^{\mathrm{II}}$ and $\mathrm{Cu}^{\mathrm{II}}$ ions in compounds $\mathbf{1}$ and 2, IR spectra, selected bond lengths and angles.

Table 1. Crystal data and structure refinements for compounds $\mathbf{1}$ and $\mathbf{2}$.

\begin{tabular}{|c|c|c|}
\hline & 1 & 2 \\
\hline Formula & $\mathrm{C}_{21} \mathrm{H}_{30} \mathrm{CuN}_{2} \mathrm{O}_{9} \mathrm{P}_{2}$ & $\mathrm{C}_{47} \mathrm{H}_{64} \mathrm{~N}_{5} \mathrm{Ni}_{2} \mathrm{O}_{25} \mathrm{P}_{4}$ \\
\hline Formula weight & 579.95 & 1340.33 \\
\hline Crystal system & orthorhombic & orthorhombic \\
\hline Space group & Pnma & $P 2_{1} 2_{1} 2$ \\
\hline$a / \AA ̊$ & $22.1648(4)$ & $26.570(6)$ \\
\hline$b / \AA$ & $12.9513(3)$ & $12.472(3)$ \\
\hline$c / \AA$ & $9.1479(3)$ & $18.622(4)$ \\
\hline$a 1^{\circ}$ & 90.00 & 90.00 \\
\hline$\beta /^{\circ}$ & 90.00 & 90.00 \\
\hline$\gamma /{ }^{\circ}$ & 90.00 & 90.00 \\
\hline $\mathrm{Z}$ & 4 & 4 \\
\hline$V / \AA^{3}$ & $2626.02(12)$ & $6171(2)$ \\
\hline Density $/ \mathrm{g} \cdot \mathrm{cm}^{-3}$ & 1.467 & 1.443 \\
\hline$\mu / \mathrm{mm}^{-1}$ & 1.004 & 0.795 \\
\hline$F(000)$ & 1204 & 2788 \\
\hline Reflections collected/unique & $10533 / 2644 / 0.0513$ & $23072 / 10160 / 0.1674$ \\
\hline Data / restraints / parameters & 2644 / 6 / 182 & $10160 / 42$ / 757 \\
\hline Final $R$ indices $\left[R_{1}>2 \sigma(I)\right]$ & $R_{1}=0.0666$ & $R_{1}=0.0845$ \\
\hline & $w R_{2}=0.1447$ & $w R_{2}=0.1460$ \\
\hline GOF on $F^{2}$ & 1.084 & 1.028 \\
\hline Largest diff. peak and hole $/ \mathrm{e} \cdot \AA^{-3}$ & 0.800 and -0.716 & 0.575 and -0.566 \\
\hline
\end{tabular}




\section{Acknowledgements}

We thank the National Natural Science Foundation of China (21171173, 21173246) and the Hundred-talent Project (KJCX2-YWW34) of the Chinese Academy of Sciences for the financial support.

\section{References}

[1] O. K. Farha, A. O. Yazaydin, I. Eryazici, C. D. Malliakas, B. G. Hauser, M. G. Kanatzidis, S. T. Nguyen, R. Q. Snurr, J. T. Hupp, Nat. Chem. 2010, 2, 944-948.

[2] a) J. R. Li, J. Sculley, H. C. Zhou, Chem. Rev. 2012, 112, 869932; b) Y. Q. Lan, H. L. Jiang, S. L. Li, Q. Xu, Adv. Mater. 2011, 23, 5015-5020; c) S. Couck, J. F. M. Denayer, G. V. Baron, T. Remy, J. Gascon, F. Kapteijn, J. Am. Chem. Soc. 2009, 131, 6326-6327.

[3] a) P. F. Ai, L. Chen, Y. T. Guo, S. Y. Jie, B. G. Li, J. Organomet. Chem. 2012, 705, 51-58; b) Y. Lu, M. Tonigold, B. Bredenkötter, D. Volkmer, J. Hitzbleck, G. Langstein, Z. Anorg. Allg. Chem. 2008, 634, 2411-2417.

[4] M. C. Das, Q. S. Guo, Y. B. He, J. Kim, C. G. Zhao, K. L. Hong, S. C. Xiang, Z. J. Zhang, K. M. Thomas, R. Krishna, B. L. Chen, J. Am. Chem. Soc. 2012, 134, 8703-8710.

[5] a) P. Roy, M. Manassero, K. Dhara, P. Banerjee, Polyhedron 2009 , 28, 1133-1137; b) Q.-L. Zhu, T.-L. Sheng, R.-B. Fu, S.-M. Hu, L. Chen, C.-J. Shen, X. Ma, X.-T. Wu, Chem. Eur. J. 2011, 17, 3358-3362; c) Z. Wang, F. Y. Bai, Y. H. Xing, Y. Xie, M. F. Ge, S. Y. Niu, Z. Anorg. Allg. Chem. 2010, 636, 1570-1575.

[6] a) W. Ouellette, A. V. Prosvirin, J. Valeich, K. R. Dunbar, J. Zubieta, Inorg. Chem. 2007, 46, 9067-9082; b) C.-M. Liu, D.-Q. Zhang, D.-B. Zhu, Inorg. Chem. 2009, 48, 4980-4987; c) J.-C. Liu, X. Guo, J.-S. Huang, X.-Z. You, Inorg. Chem. 2002, 41, 235-243; d) E. Q. Gao, J. K. Tang, D. Z. Liao, Z. H. Jiang, S. P. Yan, G. L. Wang, Inorg. Chem. 2001, 40, 3134-3140; e) A. Escuer, R. Vicente, S. B. Kumar, X. Solans, M. FontBardia, A. Caneschi, Inorg. Chem. 1996, 35, 3094-3098; f) J. Tercero, C. Diaz, J. Ribas, M. Maestro, J. Mahia, H. Stoeckli-Evans, Inorg. Chem. 2003, 42, 3366-3373.

[7] J. J. Perry, J. A. Perman, M. J. Zaworotko, Chem. Soc. Rev. 2009, 38, 1400-1417.

[8] K. J. Gagnon, H. P. Perry, A. Clearfield, Chem. Rev. 2012, 112, 1034-1054.

[9] G. K. H. Shimizu, R. Vaidhyanathan, J. M. Taylor, Chem. Soc. Rev. 2009, 38, 1430-1449.

[10] C.-I. Yang, Y.-T. Song, Y.-J. Yeh, Y.-H. Liu, T.-W. Tseng, K.-L. Lu, CrystEngComm 2011, 13, 2678-2686.
[11] J. Zhang, Y.-S. Xue, H.-M. Wang, M. Fang, H.-B. Du, Y.-Z. Li, X.-Z. You, Inorg. Chim. Acta 2012, 392, 148-153.

[12] A. Distler, D. L. Lohse, S. C. Sevov, J. Chem. Soc. Dalton Trans. 1999, 1805-1812.

[13] D.-K. Cao, S. Gao, L.-M. Zheng, J. Solid State Chem. 2004, 177, 2311-2315.

[14] a) M. T. Wharmby, J. P. S. Mowat, S. P. Thompson, P. A. Wright, J. Am. Chem. Soc. 2011, 133, 1266-1269; b) X. M. Zhao, K. R. Ma, Y. Zhang, X. J. Yang, M. H. Cong, Inorg. Chim. Acta 2012, 388, 33-36; c) P. O. Adelani, T. E. Albrecht-Schmitt, Cryst. Growth Des. 2011, 11, 4227-4237; d) P. DeBurgomaster, W. Ouellette, H. Liu, C. J. O'Connor, J. Zubieta, CrystEngComm 2010, 12, 446-469; e) J.-G. Mao, Z. Wang, A. Clearfield, J. Chem. Soc. Dalton Trans. 2002, 4457-4463.

[15] J.-R. Li, A. A. Yakovenko, W. Lu, D. J. Timmons, W. Zhuang, D. Yuan, H.-C. Zhou, J. Am. Chem. Soc. 2010, 132, 17599-17610.

[16] a) R. Banerjee, A. Phan, B. Wang, C. Knobler, H. Furukawa, M O'Keeffe, O. M. Yaghi, Science 2008, 319, 939-943; b) W. Morris, B. Leung, H. Furukawa, O. K. Yaghi, N. He, H. Hayashi, Y. Houndonougbo, M. Asta, B. B. Laird, O. M. Yaghi, J. Am. Chem. Soc. 2010, 132, 11006-11008.

[17] S. Ma, D. Sun, D. Yuan, X.-S. Wang, H.-C. Zhou, J. Am. Chem. Soc. 2009, 131, 6445-6451.

[18] M. Yuan, S. Gao, H.-L. Sun, G. Su, Inorg. Chem. 2004, 43, 82218223

[19] a) A. W. Addison, T. N. Rao, J. Reedijk, J. van Rijn, G. C. Verschoor, J. Chem. Soc. Dalton Trans. 1984, 1349-1356; b) A. Rodriguez-Dieguez, M. E. Lopez-Viseras, J. E. Perea-Buceta, A. J. Mota, E. Colacio, Inorg. Chim. Acta 2012, 385, 73-80.

[20] V. K. Muppidi, P. S. Zacharias, S. Pal, J. Solid State Chem. 2007, 180, 132-137.

[21] M. J. Zaworotko, Chem. Commun. 2001, 1-9.

[22] a) K. N. Power, T. L. Hennigar, M. J. Zaworotko, New J. Chem. 1998, 22, 177-181; b) M. Kondo, T. Yoshitomi, K. Seki, H. Matsuzaka, S. Kitagawa, Angew. Chem. Int. Ed. Engl. 1997, 36, $1725-1727$.

[23] A. W. Van der Made, R. H. Van der Made, J. Org. Chem. 1993 $58,1262-1263$.

[24] SAINT, Version 6.45, Bruker Analytical X-ray Systems Inc., 2003

[25] SADABS, Version 2.10; Bruker AXS Inc., 2003.

[26] G. M. Sheldrick, SHELXS-97, Program for Crystal Structure Determination, University of Göttingen, Göttingen, Germany 1997.

[27] G. M. Sheldrick, SHELXL-97, Program for Crystal Structure Refinement, University of Göttingen, Göttingen, Germany 1997.

Received: April 2, 2013 Published Online: June 12, 2013 